\title{
STUDI KOMPARASI PERILAKU STRUKTUR SISTEM RANGKA BERPENGAKU EKSENTRIK TIPE D TERHADAP SISTEM RANGKA PEMIKUL MOMEN
}

\author{
Maizuar $^{1}$, Burhanuddin ${ }^{1}$ dan Burhanuddin ${ }^{2}$ \\ ${ }^{1}$ Dosen Jurusan Teknik Sipil Universitas Malikussaleh Lhokseumawe \\ ${ }^{2}$ Alumni Jurusan Teknik Sipil Universitas Malikussaleh Lhokseumawe
}

\begin{abstract}
Abstrak
Salah satu upaya mengoptimalkan kelebihan struktur baja adalah dengan menggunakan konfigurasi Sistem Rangka Berpengaku Eksentrik (SRBE) sebagai sistem rangka struktur. Penelitian ini bertujuan untuk mengetahui pengaruh penggunaan bresing eksentrik terhadap perilaku struktur dan membandingkan perilaku struktur SRPMK dan SRBE terhadap beban gempa. Dalam studi ini didesain sebuah portal baja beraturan menggunakan bresing tipe D dengan jumlah lantai 10. Perencanaan didasarkan pada SNI 03-17292002 dan SNI 03-1726-2003. Sebagai pembanding turut didesain gedung yang sama namun tanpa menggunakan bresing agar dapat dilihat pengaruh penambahan bresing eksentrik terhadap struktur tersebut ketika bekerja beban gempa. Hasil analisis menunjukkan bahwa SRPMK dan SRBE memiliki pola mode shape yang hampir sama. Penambahan bresing secara nyata dapat meningkatkan kapasitas struktur terhadap beban lateral secara umum sebesar $28,317 \%$ pada sumbu X dan 20,133\% pada sumbu Y. Struktur SRBE memiliki kekakuan elastik dan pasca-elastik serta mekanisme pelelehan yang lebih baik dibandingkan struktur SRPMK.
\end{abstract}

Kata Kunci : Komparasi, Perilaku, SRPMK, SRBE

\section{Pendahuluan}

Sistem rangka pemikul momen (SRPM) mempunyai kemampuan menyerap energi gempa yang baik. Penyerapan energi tersebut memerlukan terjadinya simpangan yang cukup besar, sehingga dapat menyebabkan kerusakan nonstruktural yang besar. Pengembangan dari SRPM adalah sistem rangka bresing konsentrik (SRBK) yang memiliki kekakuan yang cukup baik dengan adanya elemen pengaku. Sistem ini dinilai kurang dari segi penyerapan energi karena kapasitas inelastik dari elemen bresing yang dinilai kurang. Kekurangan pada sistem SRBK dalam menerima beban lateral ini diatasi dengan munculnya sistem rangka bresing eksentris (SRBE). Sistem portal ini mempunyai nilai daktilitas yang lebih tinggi dibandingkan SRBK yang lebih mengutamakan kekakuan struktur. Tingginya nilai daktilitas pada SRBE disebabkan oleh adanya elemen yang berfungsi sebagai pendisipasi energi ketika struktur menerima beban lateral (beban gempa). Elemen ini adalah segmen balok yang dinamakan link.

Salah satu metode analisis yang dapat digunakan untuk mengetahui perilaku struktur terhadap gempa adalah menggunakan analisis dinamik riwayat waktu (Time History Analysis). Analisis dinamik riwayat waktu dipandang sebagai metode analisis struktur yang paling memuaskan saat ini karena analisis ini menggunakan data rekaman gempa (Accelerogram) untuk mensimulasikan beban gempa yang bekerja pada struktur. Dengan metode ini pengaruh kekakuan, inersia deformasi struktur serta karakteristik beban gempa yang bersifat bolak-balik dapat diselesaikan dengan lebih akurat dibandingkan dengan analisis statik.

Studi Komparasi Perilaku Struktur Sistem Rangka Berpengaku Eksentrik Tipe D 
Dalam studi ini didesain sebuah portal baja beraturan menggunakan pengaku eksentrik (Sistem Rangka Berpengaku Eksentrik/ SRBE) tipe D dengan jumlah lantai 10. Perencanaan didasarkan pada SNI-03-1729-2002 (Tata Cara Perencanaan Struktur Baja Untuk Bangunan Gedung), serta SNI 03-1726-2003 (Tata Cara Perencanaan Ketahan Gempa Untuk Bangunan Gedung). Sebagai pembanding turut didesain gedung yang sama namun tanpa menggunakan bresing agar dapat dilihat pengaruh penambahan bresing eksentrik terhadap struktur tersebut ketika bekerja beban gempa. Pemodelan dan analisis struktur dilakukan dengan menggunakan software SAP2000 v.14.1.

\section{Tinjauan Pustaka}

\subsection{Sistem Rangka Pemikul Momen (SRPM)}

Sistem rangka pemikul momen adalah suatu sistem struktur yang pada dasarnya memiliki rangka ruang pemikul beban gravitasi secara lengkap, beban lateral dipikul oleh rangka ruang tersebut terutama melalui mekanisme lentur elemen penyusunnya (SNI 03-1726-2003).

Sistem rangka pemikul momen mempunyai daktilitas dan penyerapan energi yang bagus namun pada umumnya tidak memiliki kekakuan yang cukup terhadap gaya lateral. Sebaliknya jika struktur tersebut direncanakan agar memiliki kekakuan yang cukup maka akan menghilangkan nilai-nilai ekonomis yang dimiliki struktur (Quo dan Jin, 2007).

\subsection{Sistem Rangka Berpengaku Eksentrik (SRBE)}

Sistem rangka berpengaku eksentrik (SRBE) adalah sistem dimana pengaku tidak terhubung ke perpotongan balok dan kolom melainkan terhubung ke balok dengan jarak " $e$ " ke titik perpotongan balok dan kolom. Segmen balok pendek ini memiliki daktilitas tinggi yang memastikan struktur memiliki perilaku inelastis serta penyerapan energi yang bagus (Popov dan Roeder 1978).

Menurut Becker dan Ishler (1996), penelitian telah menunjukkan Sistem rangka berpengaku eksentrik (SRBE) memiliki kekakuan elastik yang hampir sebanding dengan struktur sistem rangka berpengaku konsentrik (SRBK), terutama jika digunakan link pendek. Kekakuan lateral struktur SRBE adalah fungsi dari link, semakin pendek link yang digunakan maka struktur SRBE akan semakin kaku. Demikian juga sebaliknya, semakin panjang link maka struktur SRBE akan semakin fleksibel. Salah satu konfigurasi struktur SRBE diperlihatkan pada Gambar 1.

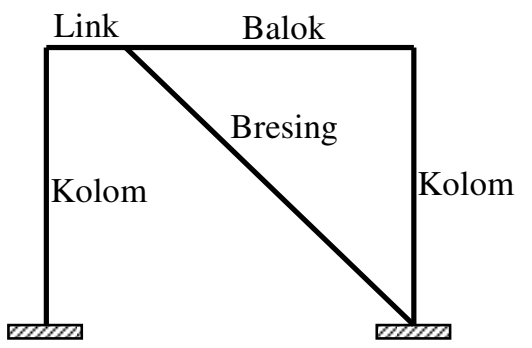

Gambar 1. Konfigurasi SRBE Tipe D

Sumber: AISC 341-05

Studi Komparasi Perilaku Struktur Sistem Rangka Berpengaku Eksentrik Tipe D 
Menurut Guo dan Jin (2007), mekanisme kerja SRBE berbeda pada tiap intensitas gempa yang berbeda. Pada gempa dengan intensitas kecil hingga moderat, kekakuan lateral struktur cenderung berasal dari pengaku eksentrik dimana elemen tersebut berperilaku layaknya pengaku konsentrik pada sistem rangka berpengaku konsentrik (SRBK). Pada gempa dengan intensitas besar, pelelehan akibat gaya geser pada link akan menyerap energi gempa serta mencegah terjadinya tekuk akibat gaya tekan pada pengaku eksentrik.

\subsection{Kondisi Batas Link}

Link adalah elemen yang berperilaku sebagai balok pendek yang pada kedua sisinya bekerja gaya geser dengan arah yang berlawanan serta momen yang diakibatkan oleh gaya geser tersebut (Roeder dan Popov, 1978).

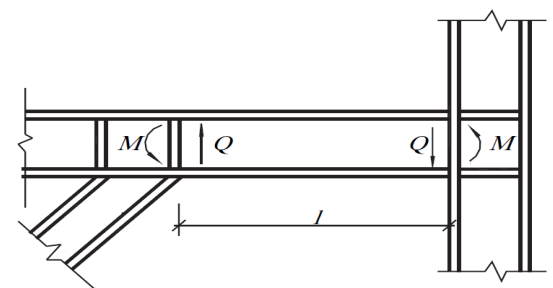

\section{Gambar 2. Gaya-gaya pada link} Sumber: Quo dan Jin, 2007

Perilaku link pada suatu sistem SRBE dapat berupa Moment Link (link momen) atau Shear Link (link geser) tergantung dari panjang elemen link tersebut. Jenis link berdasarkan panjangnya adalah sebagai berikut:

1. Link geser murni, $\mathrm{e} \leq 1,6 \mathrm{Mp} / \mathrm{Vp}$.

Jenis link ini leleh akibat geser pada respon/ deformasi inelastis.

2. Link dominan geser, $1,6 \mathrm{Mp} / \mathrm{Vp} \leq \mathrm{e} \leq 2,6 \mathrm{Mp} / \mathrm{Vp}$.

Jenis link ini leleh akibat dominasi geser (pada kombinasi geser dan lentur) pada respon/ deformasi inelastis.

3. Link dominan lentur, $2,6 \mathrm{Mp} / \mathrm{Vp} \leq \mathrm{e} \leq \mathrm{Vp} 5 \mathrm{Mp} / \mathrm{Vp}$.

Jenis link ini leleh akibat dominasi lentur (pada kombinasi geser dan lentur) pada respon/ deformasi inelastis.

4. Link lentur murni, e $\geq 5 \mathrm{Mp} / \mathrm{Vp}$.

Jenis link ini leleh akibat lentur pada respon/ deformasi inelastis.

Kekuatan atau kondisi batas link geser dan link momen didefinisikan sebagai berikut:

$$
\begin{aligned}
& M_{p}=Z_{x} \cdot f_{y} \\
& V_{p}=0,6 \cdot f_{y} \cdot\left(h-2 t_{f}\right)
\end{aligned}
$$

di mana: $\quad M_{p}=$ momen plastis penampang $(\mathrm{Nmm})$

$Z_{x}=$ modulus plastis penampang $\left(\mathrm{mm}^{3}\right)$

$f_{y}=$ tegangan leleh baja $(\mathrm{MPa})$

$V_{p}=$ gaya geser plastis penampang $(\mathrm{N})$

$h=$ tinggi penampang $(\mathrm{mm})$

$t_{f}=$ tebal sayap $(\mathrm{mm})$

$t_{w}=$ tebal badan (mm)

Studi Komparasi Perilaku Struktur Sistem Rangka Berpengaku Eksentrik Tipe D 
Berdasarkan SNI 03-1729-2002, link yang digunakan harus memenuhi persyaratan perbandingan lebar terhadap tebal untuk penampang kompak. Kuat rencana link geser direncanakan berdasarkan kondisi batas leleh geser adalah sebagai berikut:

$$
V_{n}=\varnothing V_{p}
$$

di mana: $\quad V=$ nilai minimum dari $V_{p}$ atau $2 M_{p} / e$

$\varnothing=0,9$

$e \quad=$ panjang link $(\mathrm{mm})$

Pengaruh gaya aksial terhadap kuat geser rencana link dapat diabaikan apabila gaya aksial terfaktor yang bekerja pada link tidak melebihi $15 \%$ dari kuat leleh aksial nominal link.

$$
P_{u} \leq 0,15 P_{y}
$$

di mana: $\quad P_{u}=$ beban aksial terfaktor akibat kombinasi beban $(\mathrm{N})$

$P_{y}=$ kuat leleh aksial nominal $(\mathrm{N})$

\subsection{Sudut Rotasi Link}

Sudut rotasi link adalah sudut inelastis antara link dan balok di luar link ketika peralihan lantai total sama dengan peralihan lantai rencana (AISC 341-05). Menurut Popov (1989), dalam perencanaan SRBE, titik belok biasanya diasumsikan terjadi di link. Secara teoritis titik belok ini berjarak $M p / V p$ dihitung dari pengaku.

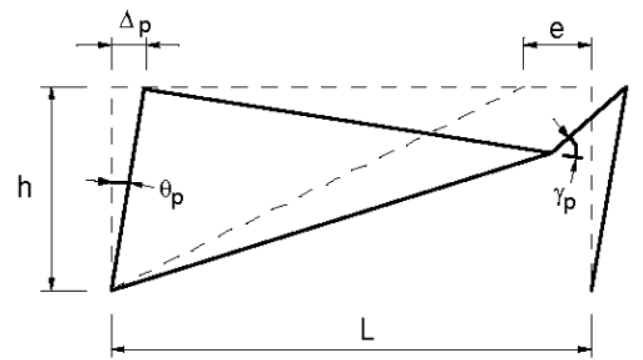

\section{Gambar 3. Sudut Rotasi link SRBE tipe D}

Sumber: AISC 341-05

Sudut Rotasi link dihitung berdasarkan defleksi lateral yang terjadi sesuai dengan geometri rangka (AISC 341-05). Untuk struktur SRBE yang menggunakan link tunggal pada tiap tingkatnya, sudut rotasi link dihitung dengan persamaan:

$$
\gamma_{p}=\frac{L}{e} \theta_{P}=\frac{L \cdot \Delta_{P}}{e \cdot h}
$$

di mana:

$\gamma_{p}=$ sudut rotasi link (radian),

$L=$ lebar bentang $(\mathrm{mm})$

$\Delta_{p}=$ tinggi lantai $(\mathrm{mm})$

$h=$ tinggi lantai $(\mathrm{mm})$

Studi Komparasi Perilaku Struktur Sistem Rangka Berpengaku Eksentrik Tipe D 
SNI 03-1729-2002 mensyaratkan sudut rotasi link tidak melebihi nilai-nilai berikut:

- 0,08 radian untuk e $\leq 1,6 \mathrm{Mp} / \mathrm{Vp}$

- 0,02 radian untuk e $\geq 2,6 \mathrm{Mp} / \mathrm{Vp}$

Nilai untuk panjang link antara $1,6 \mathrm{Mp} / \mathrm{Vp}$ dan $2,6 \mathrm{Mp} / \mathrm{Vp}$ ditentukan melalui interpolasi linear.

\subsection{Analisis Dinamik Riwayat Waktu}

Analisis dinamik riwayat waktu adalah suatu langkah-langkah analisis respon dinamik struktur terhadap beban yang bervariasi terhadap waktu. Analisis ini dapat berupa analisis linear maupun nonlinear (CSI Analysis Reference Manual, 2009).

Menurut Chopra (2007), pada daerah jangkauan gempa, masalah utama dari analisis dinamik adalah perilaku struktur terhadap gempa yang bersumber dari pergerakan muka tanah.

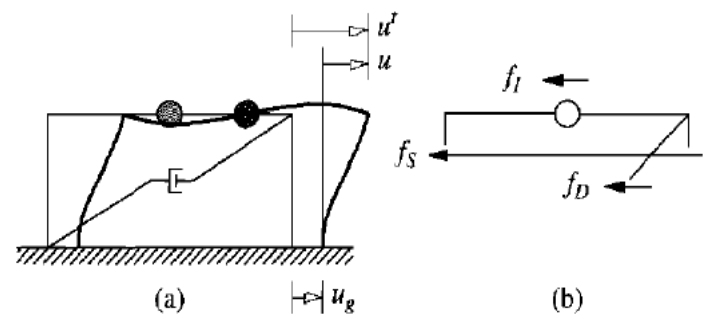

\section{Gambar 4. Pemodelan Perpindahan Massa Akibat Pergerakan Tanah} Sumber: Chopra, 2007

Persamaan gerakan (Equation Of Motion) yang mengakibatkan perpindahan relatif pada struktur elastik adalah sebagai berikut:

$$
m \ddot{u}+c \dot{u}+k u=-m \ddot{u}_{g(t)}
$$

Untuk struktur inelastik dimana perpindahan tidak merupakan suatu nilai yang tunggal maka persamaan diatas menjadi:

$$
m \ddot{u}+c \dot{u}+f_{s}(u, \dot{u})=-m \ddot{u}_{g(t)}
$$

Penyelesaian persamaan diatas untuk mendapatkan nilai perpindahan dilakukan dengan Integrasi Duhamel sebagai berikut:

$$
u_{(t)}=\frac{1}{m \omega_{n}} \int_{0}^{t} p_{t} \sin \left[\omega_{n}(t-\tau)\right] d \tau
$$

\section{Metode Penelitian}

\subsection{Geometri Bangunan}

Gedung yang akan dianalisis adalah gedung hipotetis kategori gedung beraturan dengan ukuran denah $25 \mathrm{~m}$ x $16 \mathrm{~m}$. Gedung ini terdiri atas 10 lantai, dengan tinggi masing-masing lantai adalah $4 \mathrm{~m}$.

Studi Komparasi Perilaku Struktur Sistem Rangka Berpengaku Eksentrik Tipe D 


\subsection{Dimensi Penampang}

Profil baja penampang yang digunakan pada SRBE dan SRPM adalah sama kecuali adanya penambahan elemen bresing pada SRBE. Profil baja yang digunakan pada kedua struktur adalah sebagai berikut:

- Kolom Lantai 1 - 5 : WFS 448.432.45.45

- Kolom Lantai 6 - 10 : WFS 414.405.28.18

- Balok Sumbu X : :WFS 450.200.14.9

- Balok Sumbu Y : : WFS 450.200.14.9

- Link Sumbu X dan Y : WFS 450.200.14.9

- Bresing Sumbu X dan Y : WFS 400.400.21.13

\subsection{Properti Material}

Material yang digunakan pada struktur adalah baja dengan spesifikasi sebagai berikut:

- Jenis Material : Baja

- Mutu Baja : ASTM A36 $\left(\mathrm{f}_{\mathrm{y}}=248,21 \mathrm{MPa}, \mathrm{f}_{\mathrm{u}}=372,32 \mathrm{MPa}\right)$

- Modulus Elastisitas (E) : $200000 \mathrm{MPa}$

- Rasio Poisson $(\mu) \quad: 0,3$

- Koefisien Pemuaian $(\alpha): 12 \times 10^{-6} /{ }^{0} C$

\subsection{Asumsi Desain}

Asumsi-asumsi desain yang digunakan pada pemodelan dan perencanaan struktur adalah sebagai berikut:

- Gedung difungsikan sebagai perkantoran (Faktor keutamaan $=1$ ).

- Gedung terletak di wilayah gempa 6 pada kondisi tanah lunak.

- Tebal plat lantai $12 \mathrm{~cm}$.

\subsection{Pembebanan}

Peraturan pembebanan mengacu pada Pedoman Perencanaan Pembebanan Untuk Rumah dan Gedung (PPPURG) 1987. Beban-beban yang diperhitungkan untuk desain struktur meliputi beban mati, beban hidup beban angin dan beban gempa.

\subsection{Input Akselerogram Rencana}

Analisis Time History ini dijalankan menggunakan empat buah akselerogram gempa yaitu gempa El Centro N-S (1940), gempa Taiwan (1999), gempa Kobe (1995), dan gempa Newhall (1994). Masing-masing akselerogram tersebut diskalakan ke percepatan tanah puncak wilayah gempa 6 tanah lunak yaitu $0,36 \mathrm{~g}$.

\section{Hasil Dan Pembahasan}

\subsection{Analisis Modal}

Analisis modal dilakukan untuk mendapatkan ragam getaran serta waktu getar alami alami (Mode Shape dan Natural Period) tak teredam struktur gedung terhadap ragam vibrasi bebas. Ragam alami ini merupakan suatu cerminan yang bagus terhadap perilaku struktur.

Studi Komparasi Perilaku Struktur Sistem Rangka Berpengaku Eksentrik Tipe D 
Analisis modal menunjukkan bahwa mode pertama struktur SRPMK adalah translasi arah Y dengan waktu getar alami alami 1,485 detik. Mode kedua adalah translasi arah X dengan waktu getar alami alami 1,479 detik. Mode ketiga adalah rotasi terhadap sumbu $\mathrm{Z}$ dengan waktu getar alami alami 1,340 detik.

Hasil analisis menunjukkan bahwa mode pertama struktur SRBE adalah translasi arah Y dengan waktu getar alami alami 0,999 detik. Mode kedua adalah translasi arah X dengan waktu getar alami alami 0,913 detik. Mode ketiga adalah rotasi terhadap sumbu $\mathrm{Z}$ dengan waktu getar alami alami 0,664 detik. Penurunan waktu getar alami pada struktur SRBE dibandingkan Struktur SRPMK menunjukkan bahwa penambahan bresing pada struktur dapat meningkatkan kekakuan struktur secara signifikan. Besarnya penurunan waktu getar alami tersebut juga tidak lepas dari kebutuhan untuk memenuhi persyaratan SNI 031726-2003 mengenai pembatasan waktu getar alami fundamental, selisih batasan waktu getar antara kedua tipe struktur tersebut adalah sebesar $-33,686 \%$.

Mode translasi pertama antara sumbu $\mathrm{X}$ dan Sumbu $\mathrm{Y}$ hanya berselisih 0,0065 detik atau 0,4\%, ini menunjukkan bahwa antara Sumbu X dan Sumbu Y Struktur SRPMK mempunyai poporsi kekakuan yang hampir seimbang. Poporsi kekakuan yang seperti tersebut adalah hasil dari proses perencanaan yang mana struktur direncanakan agar memiliki kekakuan yang seimbang agar dapat mengantisipasi beban gempa yang arahnya tidak bisa di prediksi. Pada struktur SRBE, mode translasi pertama Sumbu X dan Sumbu Y mempunyai selisih 0,0861 detik atau $8,61 \%$, ini menunjukkan bahwa sumbu X pada SRBE cenderung lebih kaku dibandingkan sumbu Y. Ini terjadi karena kekakuan struktur SRBE merupakan fungsi dari panjang link dan panjang link digunakan poporsional terhadap panjang masing-masing balok.

Hasil analisis menunjukkan kedua struktur urutan tipe mode yang sama yaitu mode ke-1 translasi arah $\mathrm{Y}$, mode ke-2 translasi arah $\mathrm{X}$, mode ke-3 rotasi terhadap sumbu Z, mode ke-4 translasi arah Y dan mode ke-5 translasi arah X.

Gambar 5 menunjukkan bahwa tidak ada perbedaan yang signifikan pada pola mode shape kedua struktur. Hal ini menunjukkan walaupun struktur SRBE mempunyai elemen bresing namun, masih menyimpan sifat-sifat yang dimiliki oleh SRPMK.

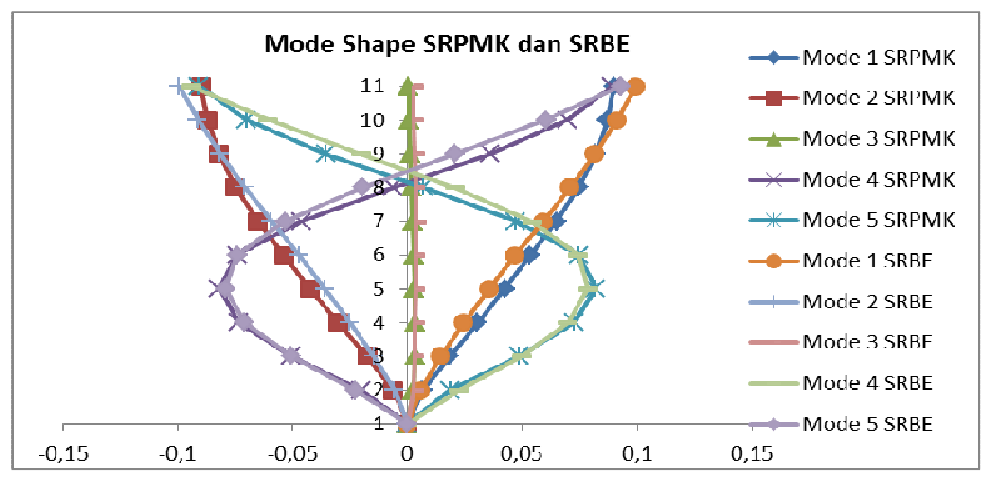

Gambar 5. Mode Shape SRPMK dan SRBE

Studi Komparasi Perilaku Struktur Sistem Rangka Berpengaku Eksentrik Tipe D 


\subsection{Analisis Dinamik Riwayat Waktu}

Analisis dinamik riwayat waktu bertujuan untuk memperoleh informasi mengenai respons dinamik struktur berupa gaya yang bekerja dan deformasi yang terjadi terhadap akselerogram gempa yang digunakan. Pada kasus gempa yang digunakan cukup kuat untuk menyebabkan pelelehan pada elemen struktur, analisis ini dapat digunakan untuk mengetahui elemen yang kritis serta pola keruntuhan pada struktur tersebut

Analisis dinamik riwayat waktu dilakukan dengan SAP2000 menggunakan empat akselerogram yang diskalakan berdasarkan SNI 03-1726-2003. Output dari analisis ini berupa gaya geser dasar (Base Shear) dan peralihan (Displacement) yang terjadi pada struktur. Nilai ini merupakan gambaran kapasitas struktur terhadap beban gempa yang bekerja.

Tabel 1. Gaya geser dasar dan peralihan atap NLTHA Struktur SRPMK

\begin{tabular}{|l|c|c|c|c|}
\hline \multirow{2}{*}{ Gempa } & \multicolumn{2}{|c|}{ Sumbu X } & \multicolumn{2}{c|}{ Sumbu Y } \\
\cline { 2 - 5 } & $\begin{array}{c}\text { Base } \\
\text { Shear } \\
\text { (ton) }\end{array}$ & $\begin{array}{c}\text { Roof } \\
\text { Displacement } \\
(\mathbf{m})\end{array}$ & $\begin{array}{c}\text { Base Shear } \\
\text { (ton) }\end{array}$ & $\begin{array}{c}\text { Roof } \\
\text { Displacement } \\
(\mathbf{m})\end{array}$ \\
\hline El Centro N-S & 488,303 & 0,161 & 472,896 & 0,162 \\
\hline Kobe & 679,285 & 0,259 & 661,276 & 0,263 \\
\hline New Hall & 887,148 & 0,370 & 881,765 & 0,372 \\
\hline Taiwan & 1000,468 & 0,354 & 967,097 & 0,358 \\
\hline
\end{tabular}

Peralihan terbesar terjadi pada gempa New Hall sumbu Y yaitu sebesar $0,372 \mathrm{~m}$ dengan gaya geser dasar sebesar 881,765 ton. Hal ini dikarenakan sumbu Y merupakan sumbu lemah struktur.

Tabel 2. Gaya geser dasar dan peralihan atap NLTHA Struktur SRBE

\begin{tabular}{|l|c|c|c|r|}
\hline \multirow{2}{*}{ Gempa } & \multicolumn{2}{|c|}{ Sumbu X } & \multicolumn{2}{c|}{ Sumbu Y } \\
\cline { 2 - 5 } & $\begin{array}{c}\text { Base Shear } \\
\text { (ton) }\end{array}$ & $\begin{array}{c}\text { Roof } \\
\text { Displacement } \\
(\mathbf{m})\end{array}$ & $\begin{array}{c}\text { Base Shear } \\
\text { (ton) }\end{array}$ & $\begin{array}{c}\text { Roof } \\
\text { Displacement } \\
(\mathbf{m})\end{array}$ \\
\hline El Centro N-S & 1070,064 & 0,133 & 966,582 & 0,149 \\
\hline Kobe & 1075,302 & 0,189 & 884,366 & 0,199 \\
\hline New Hall & 1104,057 & 0,205 & 1113,936 & 0,183 \\
\hline Taiwan & 1167,601 & 0,148 & 1237,413 & 0,184 \\
\hline
\end{tabular}

Peralihan terbesar terjadi pada gempa New Hall sumbu Y yaitu sebesar 0,183 m dengan gaya geser dasar sebesar 1113,936 ton. Hal ini dikarenakan sumbu Y merupakan sumbu lemah struktur 
Penggunaan bresing pada struktur akan dapat meningkatkan kapasitas struktur. hal ini terlihat dari penurunan peralihan yang terjadi pada struktur SRBE dibandingkan struktur SRPMK. Penggunaan bresing akan juga meningkatkan kapasitas struktur secara keseluruhan. Meskipun struktur SRBE mengalami pelelehan terlebih dahulu, namun pada struktur SRBE terjadi peningkatan gaya geser pada saat runtuh.

\section{Kesimpulan}

Dari hasil analisis dan pembahasan yang telah dilakukan maka dapat diambil beberapa kesimpulan sebagai berikut:

1. Perencanaan struktur SRPMK yang memenuhi pembatasan waktu getar alami SNI 03-1726-2003 menghasilkan struktur yang boros dari segi rasio kuat perlu terhadap kuat nominal.

2. Struktur SRPMK dan SRBE memiliki pola mode shape yang sama.

3. Dari hasil analisis dinamik riwayat waktu, dapat disimpulkan bahwa, struktur SRBE cocok didesain pada daerah dengan gempa ekstrim karena peningkatan kapasitas dinamik lebih besar terlihat pada gempa yang ekstrim (New Hall dan Taiwan) dari pada gempa sedang (El Centro N-S dan Kobe).

4. Struktur SRBE memiliki kekakuan elastik dan pasca-elastik yang lebih baik dibandingkan struktur SRPMK.

5. Mekanisme pelelehan yang terjadi pada struktur SRBE lebih baik dibandingkan struktur SRPMK.

6. Karakteristik akselerogram sangat berpengaruh terhadap besar beban gempa yang bekerja pada struktur.

\section{Daftar Kepustakaan}

1. Anonim, 1983, Pedoman Perencanaan Pembebanan Untuk Rumah dan Gedung (SKBI 1.3.53.1987), Departemen Pekerjaan Umum, Jakarta.

2. Anonim, 2002, Tata Cara Perencanaan Struktur Baja Untuk Bangunan Gedung (SNI 03-1729-2002), Departemen Pekerjaan Umum, Jakarta.

3. Anonim, 2003, Tata Cara Perencanaan Tata Cara Perencanaan Ketahanan Gempa Untuk Bangunan Gedung (SNI 03-1726-2003), Departemen Kimpraswil, Bandung.

4. Anonim, 2009, CSI Analysis Reference for SAP2000 ${ }^{\odot}$, ETABS $^{\odot}$ and $\boldsymbol{S A F E}{ }^{\odot}$, Computer and Structure, Inc., California.

5. Becker, Roy, Michael Ishler, 1996, Seismic Design Practice For Eccentrically Braced Frame (Based on The 1994 UBC), Structural Steel Educational Council, http://www.steeltips.org/steeltips/index.php

6. Chopra, Anil. K., 2007, Dynamics of Structure $3^{\text {rd }}$ Edition, Pearson Prentice Hall, New Jersey.

7. Li, Guo-Qiang dan Jin-Jun Li, 2007, Advance Analysis and Design of Steel Frame, John Wiley and Sons Ltd., West Sussex.

8. Peacock, Philips dan Alan Hart, 2003, Steel Designer's Manual Chapter 2: Multi-storey Building, Blackwell Publishing, Oxford.

9. Roeder, C.W. dan Popov, E.P., 1978, Eccentrically Braced Steel Frames for Earthquakes, ASCE Vol. 104, New York. 